
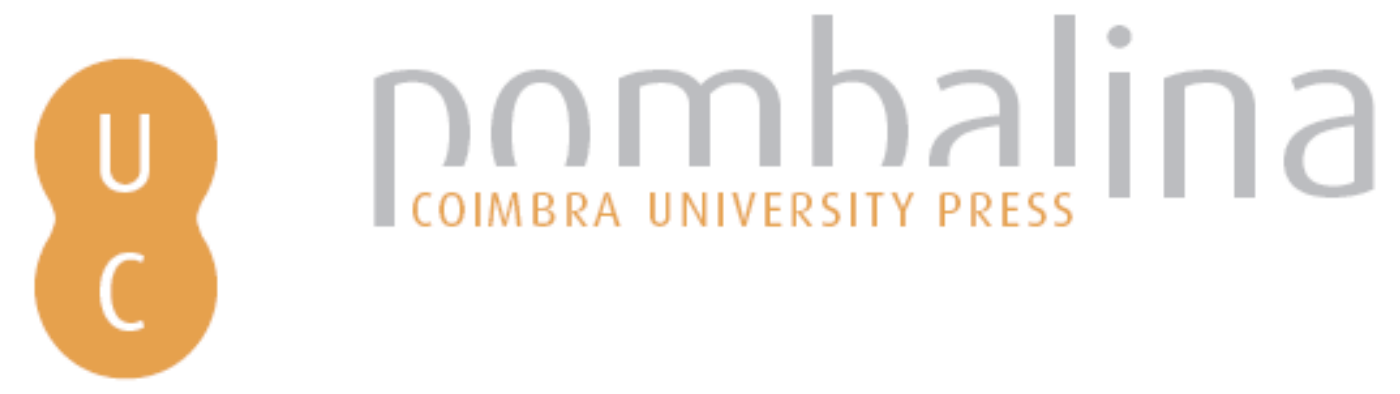

\title{
El límite de Alberto de Zavalía: Antígona y la antinomia civilización y barbarie
}

\author{
Autor(es): $\quad$ Biglieri, Aníbal A.
}

Publicado por: Imprensa da Universidade de Coimbra; Annablume

URL

persistente: $\quad$ URI:http://hdl.handle.net/10316.2/40925

DOI: $\quad$ DOI:https://doi.org/10.14195/978-989-26-1298-0_19

Accessed : $\quad$ 26-Apr-2023 14:33:05

A navegação consulta e descarregamento dos títulos inseridos nas Bibliotecas Digitais UC Digitalis, UC Pombalina e UC Impactum, pressupõem a aceitação plena e sem reservas dos Termos e Condições de Uso destas Bibliotecas Digitais, disponíveis em https://digitalis.uc.pt/pt-pt/termos.

Conforme exposto nos referidos Termos e Condições de Uso, o descarregamento de títulos de acesso restrito requer uma licença válida de autorização devendo o utilizador aceder ao(s) documento(s) a partir de um endereço de IP da instituição detentora da supramencionada licença.

Ao utilizador é apenas permitido o descarregamento para uso pessoal, pelo que o emprego do(s) título(s) descarregado(s) para outro fim, designadamente comercial, carece de autorização do respetivo autor ou editor da obra.

Na medida em que todas as obras da UC Digitalis se encontram protegidas pelo Código do Direito de Autor e Direitos Conexos e demais legislação aplicável, toda a cópia, parcial ou total, deste documento, nos casos em que é legalmente admitida, deverá conter ou fazer-se acompanhar por este aviso. 


\section{O Livro do Tempo: \\ Escritas e reescritas}

\section{Teatro Greco-Latino e sua recepção II}

Maria de Fátima Silva, Maria do Céu

Fialho \& José Luís Brandão (coords.)

IMPRENSA DA UNIVERSIDADE DE COIMBRA 


\section{El límite de Alberto de Zavalía: \\ ANTÍgONA Y LA ANTINOMIA CIVILIZACIÓN Y BARBARIE ${ }^{1}$ \\ (El limite by Alberto de Zavalía: Antigone and autonomy of civilization and barbarism)}

Aníbal A. Biglieri (anibal.biglieri1@uky.edu)
University of Kentucky

Resumen - El límite de Alberto de Zavalía reescribe el mito de Antígona con la muerte de Marco Manuel de Avellaneda, ejecutado por su oposición a Juan Manuel de Rosas. Contra las órdenes del general Manuel Oribe, Fortunata García roba la cabeza del degollado, expuesta en la plaza de Tucumán, y le da sepultura.

Palabras clave - El limite, Zavalía, Antígona, civilización, barbarie.

Abstract - Alberto de Zavalía's El limite reworks Antigone's myth with Marco Manuel de Avellaneda's death, executed because of his opposition to Juan Manuel de Rosas. Against General Manuel Oribe's orders, Fortunata García takes Avellaneda's head, exposed in Tucumán's main square, and buries it.

Keywords - El límite, Zavalía, Antigone, civilization, barbarism.

\section{RECEPCIÓN DE LOS CLÁSICOS}

En Latinoamérica, se ha registrado casi una treintena de Antígonas diferentes (Pianacci 2008: 76) y en la Argentina, por lo menos, se han escrito ocho versiones, entre ellas Antígona Vélez, de Leopoldo Marechal (1900-1970), El límite, de Alberto de Zavalía (1911-1988), y La cabeza en la jaula, de David Cureses (1935-2006), dramas estrenados, respectivamente, en los años 1951, 1958 y 1963. Los tres retoman el drama sofocleo, en la segunda mitad del siglo $\mathrm{XX}$, para ofrecer sus interpretaciones de ciertos acontecimientos del pasado argentino y colombiano acaecidos en el siglo precedente, basadas en la antinomia entre civilización y barbarie, constante en el pensamiento argentino desde que fue expuesta por Domingo F. Sarmiento en Facundo o civilización y barbarie, libro publicado en 1845, durante el gobierno de Juan Manuel de Rosas (1835-1852).

La pregunta de George Steiner "Why a hundred 'Antigones' after Sophocles?" no ha perdido su vigencia a lo largo de milenios: “... why -se pregunta también- it should be that a handful of ancient Greek myths continue to

${ }^{1}$ Otra versión de este análisis de El límite se encuentra incluida en nuestro artículo "Antigone, Medea, and Civilization and Barbarism in Spanish American History", in Van Zyl Smit, B. (ed.) (2016), A Handbook to the Reception of Greek Drama. Malden, MA: John Wiley \& Sons, pp. 348-63. 
dominate, to give vital shape to our sense of self and of the world?" (Steiner 1996: ix, 121). En lo que respecta a la Argentina y a estos dramaturgos, ¿por qué y para qué volver a Sófocles (496-406 AC) para replantear, una vez más, el conflicto entre civilización y barbarie? La reelaboración del teatro clásico obliga también a preguntarse por la recepción que en la actualidad tienen obras escritas en Grecia hace milenios, a reflexionar por qué se da este fenómeno y a estudiar de qué manera se reescribe la Antígona sofoclea, en este caso específico en la Argentina de mediados del siglo XX.

No se puede sintetizar en pocas palabras qué tienen en común las teorías de la recepción, ni menos todavía resumirlas a todas, pero sí se podría decir que su premisa básica sería, en palabras de Charles Martindale, que "to understand is always to understand historically": las obras y sus interpretaciones están siempre "situadas" en la historia y, por lo tanto, no existe un "afuera" (un "punto de Arquímedes") desde el cual se pueda entender a las primeras y proponer las segundas (Martindale 2007: 172).

Se suele explicar la pervivencia de los clásicos a lo largo de los siglos invocando la intemporalidad y "universalidad" de los mitos: así, en el caso de Antígona, el conflicto entre el individuo y el Estado es una situación "universal" que se puede repetir en todo tiempo y lugar, aunque, por supuesto, no siempre en forma idéntica. Erin B. Mee y Helene P. Foley proponen que más que de "universalidad", habría que hablar de "ubicuidad" y que la historia de Antígona es ahora mundial, y no exclusiva propiedad de Europa occidental, porque hay conflictos sociales que se reiteran periódicamente a lo largo de los tiempos (Mee and Foley 2011: 3-6).

Para explicar la perduración y ubicuidad de los mitos clásicos, Martindale propone el concepto de transhistoricidad, que se refiere no a una "naturaleza humana universal", sino más bien a fugitivas similaridades durante la historia de la humanidad y que se producen en el momento de recepción (Martindale 2007: 173, 177). Para Jean-Pierre Vernant, esta transhistoricidad de los mitos se debe a que constituían el "fondo común de la cultura, un marco de referencia no sólo para la vida religiosa, sino para otras formas de la vida social y espiritual”. Según Vernant, los mitos se pueden comparar con un "cañamazo" (canevas) en el cual se van "bordando" las narraciones orales y escritas, organizando la experiencia y formando la "atmósfera intelectual general de las sociedades arcaicas", gobernando la ética, la economía y las prácticas religiosas. También para Vernant, aun cuando parezcan entrar en contradicción, los mitos se refieren en conjunto a un lenguaje común, a un horizonte intelectual compartido, a una misma tradición patrimonio de una sociedad, en la que cada versión particular adquiere su valor en relación con todas las otras (Vernant 1974: 209-210, 214-215, 233).

Todas estas ideas se relacionan con el concepto de megatexto de Charles Segal: "a complex network of interrelated symbols, patterns, and structures that encode the values of the culture into an extensive and comprehensive system" 
(Segal 1986: 52). Pero para Segal, el megatexto no es solamente el simple agregado de símbolos, mitos, temas y textos que integran el repertorio total de una cultura, sino también constituye, dicho con sus propias palabras, las "estructuras profundas", las "pautas más o menos subconscientes” y las "afinidades temáticas" que se dan entre los mitos particulares y que apuntan, todas ellas, a la "lógica implícita del sistema" (Segal 1986: 52-53).

Ese "cañamazo" en el cual los griegos "bordaban" sus mitos (texto < textum = "tejido"), esos megatextos en los que se expresaban los valores de su cultura, pueden relacionarse también con la idea de los métarécits, cuestionada por Jean François Lyotard en La condition postmoderne. Un métarécit es una concepción "totalizante", que, con una sola mirada, abarca un sistema dado para unificarlo, totalizarlo, explicarlo y legitimizarlo. No otra sería la concepción de Sarmiento de civilización y barbarie, que explicaría el curso de la historia argentina con esa mirada "totalizante" propia de la Modernidad. Por el contrario, lo postmoderno, según Lyotard, se define ante todo por su "incrédulité à l'égard des métarécits” (Lyotard 1979: 7); pero, por otro lado, Christopher Butler recuerda que los métarécits no son solamente difíciles de evitar, sino también que casi todos los estados-naciones los tienen (Butler 2002: 13-16). La Argentina no es una excepción, ni tampoco en su teatro faltaron reelaboraciones del drama sofocleo basadas en la antinomia civilización / barbarie. Marechal, Zavalía y Cureses lo hicieron desde sus propias perspectivas y contextos, pero, por diversos que hayan sido sus condicionamientos personales e históricos de recepción de Sófocles y de producción de sus obras, compartieron un mismo "cañamazo" ideológico, un mismo megatexto o metarrelato que veía en esa dicotomía una de las claves de la historia argentina y latinoamericana. Estos autores han vuelto al mito de Antígona y a un mismo megatexto para dramatizar tres períodos diferentes de ese pasado: en La cabeza en la jaula, Cureses sitúa la acción en la ciudad colombiana de Guaduas, en los siglos XVIII/XIX; en Antígona Vélez, Marechal elige como escenario la llanura bonaerense durante la década de 1820 y en $\mathrm{El}$ límite, Zavalía traslada el drama a Tucumán, durante el período rosista. Para los tres, esta antinomia no es solamente el métarécit, sino el gran mito de la historia latinoamericana. Por razones de espacio, en este artículo, el análisis se centra en El límite de Zavalía, aunque esta problemática que aquí queda bosquejada muy resumidamente puede aplicarse también a las otras dos obras que recrean la Antígona sofoclea.

\section{EL LÍMITE}

El estreno de El limite tuvo lugar el 9 de junio de 1958 en el Teatro Sarah Bernhardt de París. La acción de esta "tragedia en dos actos" se desarrolla en la ciudad de Tucumán los días 5 y 6 de octubre de 1841 y gira en torno de darle cristiana sepultura a la cabeza de un degollado, Marco Manuel de Avellaneda, 
por su oposición al gobierno rosista. Avellaneda (1813-1841) presidía la legislatura de Tucumán en el momento de pronunciarse contra Rosas en abril de 1840, como reacción contra el asesinato del gobernador de la provincia, Alejandro Heredia, dos años antes. Coaligadas varias provincias en la "Liga del Norte", fueron derrotadas en setiembre de 1841 por Manuel Oribe (1792-1857), general uruguayo al servicio del gobierno argentino, obligando a Avellaneda a escapar hacia Jujuy. Traicionado, detenido y puesto a disposición del vencedor, fue ejecutado en San José de Metán (provincia de Salta), junto con otros oficiales de la coalición, el 3 de octubre, es decir, dos días antes de la acción de El límite. Clavada en una pica, la cabeza quedó expuesta en el centro de la Plaza Independencia de la ciudad de Tucumán. Según una tradición, Fortunata García de García (1802-1860), con la complicidad del coronel rosista Carballo, robó la cabeza y la sepultó de noche en el convento de San Francisco.

En El límite, Oribe corresponde al Creonte de Sófocles, Fortunata García, a Antígona, y Avellaneda, a Polinices. Y, siguiendo la Antígona griega, una serie de oposiciones irreconciliables se recrea en El límite, aunque ahora el conflicto enfrenta a unitarios y federales, es decir, a opositores y partidarios de Rosas, en una lucha mortal entre libertad y tiranía, civilización y barbarie. No debe sorprender, por lo tanto, que cuando el coronel Carballo, aunque admita que defienden "causas opuestas", le diga a Fortunata que "un adversario no es necesariamente un enemigo", obtenga la siguiente respuesta: "Nos hallamos librando una contienda en la que no podemos hacer ese distingo. Me cuesta considerarlo un enemigo, pero es mi deber" (Zavalía 1971: 32)2. Más aún, aunque también acepte que es posible la amistad con algunos federales, se abriría una "brecha" (o una "rendija") por donde se les podría "filtrar" la tiranía (32).

Las divisiones afectan a todos los estamentos sociales por igual. En contra de Zoila, la criada de Fortunata, su hijo Zenón es federal y para él, Avellaneda, cuya cabeza ya está expuesta en la plaza, no es más que un "salvaje unitario" (34). En la estima de Oribe, los opositores al gobierno son "inmundos unitarios" y para Zenón, este calificativo era otra forma de referirse a los enemigos del rosismo $(35,38)$.

Para unitarios como Fortunata García, el país sufría bajo el despotismo de Rosas y a este régimen se hacen numerosas referencias en El limite. La tiranía, por supuesto, lejos de ser un concepto abstracto, tiene nombres y apellidos y se encarna en el accionar de determinados individuos, el general Oribe en primer lugar, a quien Fortunata y su amiga Mercedes llaman "tirano" (33, 46, 63). Símbolos de la opresión son el color rojo vivo, o punzó, y la Sociedad Popular Restauradora, conocida mejor como "La Mazorca", creada en 1833 para

${ }^{2}$ En el resto del artículo se indicarán entre paréntesis los números de las páginas correspondientes a esta edición de El límite. 
la persecución de los enemigos del régimen, los llamados "salvajes unitarios", víctimas de asesinatos y ejecuciones sumarias. Tucumán también vivía, como el resto del país, bajo el terror inspirado por esta organización.

La tragedia de Zavalía también se basa, entre otras, en la oposición entre la tiranía con que los federales someten a los argentinos y la libertad por la que luchan los unitarios para liberarlos del rosismo. En El límite, abundan las referencias a la libertad suprimida en todo el país y en Tucumán, por el general Oribe. Símbolo de esa libertad es la cabeza de Avellaneda que Fortunata va a rescatar y sepultar durante la noche del 6 de octubre, aprovechando que en esas horas tiene lugar en su casa un baile en honor del coronel Carballo y al que asiste el mismo Oribe. Para ella, "ésta no es una cabeza más, ni la lanza es una lanza más: es la cabeza de Marco Avellaneda y es la lanza de un soldado federal. Es la cabeza de la libertad y la lanza de quien quiere asesinarla" (27). Avellaneda, "un tucumano que amó la libertad" (104), la simboliza como nadie y de allí que al "mártir de Metán” se aluda en varios pasajes de la tragedia $(27-28,54)$ como emblema de una lucha que continúa pese a todo y en la que están empeñados no sólo Fortunata, en Tucumán, sino también, en el norte del país, su esposo Domingo García, prófugo, condenado a muerte y enfermo del corazón, junto con Javier, el novio de Mercedes, y otros unitarios (41-42).

Para los opositores a la tiranía de Rosas, la lucha es, en definitiva, contra la barbarie. Y lo es también para Fortunata, quien piensa que esa cabeza expuesta en la plaza pública representa todo lo que tienen de bárbaro el régimen de Buenos Aires y sus representantes en Tucumán. Para ella, el conflicto es entre civilización y barbarie y para que no quede ninguna duda de su posición, se lo explica a su prima Laura, después de que ésta la exhorta a enfrentarse con la realidad, aceptar que la causa que defiende está perdida y salvarse como pueda (47-48). Para Fortunata, "bárbaro" no es un adjetivo forjado al calor de las luchas y pasiones políticas, sino un término que describe un estado de cosas en todo el país y al que no escapa su ciudad. Para Fortunata, Oribe es un "bárbaro" (29) y la primera impresión que le produjo Carballo fue la de "un bárbaro, un mazorquero asesino" (33), porque ¿qué otra cosa podría pensar de un coronel al servicio de Oribe y de Rosas? Pero si bien Fortunata admite su error en vista del comportamiento con que Carballo siempre se condujo en su casa, no duda en ningún momento de que los integrantes de "La Mazorca" son "bárbaros", cuyos uniformes rojos la estremecen y le causan invencible pavor (47). Pero no se trata solamente de individuos particulares, sino de un proceso de "barbarización" que afecta a toda la sociedad. En efecto, la barbarie se ha adueñado de la ciudad y no solamente los unitarios describen a los rosistas como "bárbaros", sino que ellos mismos se definen así, ante todo el mismo general Oribe, que se refiere a los federales como "montoneros bárbaros" (76).

El límite no deja ninguna duda en cuanto al contexto político y social en que una nueva Antígona se atreve a desafiar las órdenes de otro Creonte. Y 
aunque el general Oribe no lo diga explícitamente, habría encontrado en el rey de Tebas argumentos en apoyo de sus decisiones, porque ¿no podría considerarse a Avellaneda como un traidor a su patria como Polinices lo fue con la suya? ¿No es también el "mártir de Metán" indigno de un entierro (en este caso, cristiano) por haber luchado contra sus compatriotas?

En el universo dramático de Zavalía, como en el de Sófocles, se enfrentan hombres y mujeres, las esferas pública y privada, la libertad de los individuos frente a la autoridad de los gobernantes, el derecho, y el deber, de sepultar a los muertos frente a la autoridad humana que lo impide, etc. Todo es diferente en El límite, pero, en definitiva, Fortunata García y el general Oribe se enfrentan en un conflicto similar a aquel otro que puso frente a frente a la heroína sofoclea y a su tío Creonte. Las represalias serán inmediatas: el general Oribe anuncia que el responsable será fusilado al amanecer y su cabeza será puesta en la misma pica y en el mismo lugar dejado libre por Avellaneda (100). En medio del baile en casa de Fortunata, Mercedes entra en escena con la noticia del "milagro" de que la cabeza no está ya en la plaza (106) y el general Oribe, para disimular su derrota, fragua el plan de hacerle creer a la población que él mismo, conmovido en su piedad por la de Fortunata, dio orden de enterrar los restos del "ajusticiado" (107). En fin, los responsables del entierro de Avellaneda serán fusilados, marcando el triunfo de la causa federal y del gobierno de Rosas con una derrota más de sus enemigos unitarios.

Hasta aquí, el análisis de El limite se ha basado en las palabras y acciones mismas de los personajes, análisis que, por hallarse "históricamente situado", como lo postulan las teorías de la recepción, está mediado por la labor del crítico, aunque ésto no quiere decir que todo quede librado a la subjetividad y "posicionamientos ideológicos” del autor de estas páginas. Al contrario, un grado muy considerable de objetividad se puede lograr cuando, como en este caso, se ha dejado hablar a los personajes y se los ha visto actuar en una lectura más o menos directa del drama de Zavalía. También el universo dramático de El limite se basa en uno de los metarrelatos más persistentes de la historiografía argentina, según quedó apuntado. Este mito (entendido el término como un megatexto tal como Segal caracterizó a los mitos griegos) se corrobora por el simple hecho de que a él recurrió Zavalía para su obra y de que la ha escrito bajo el paradigma sarmientino se desprende no solamente de los análisis precedentes, sino, más sencillamente, porque el mismo dramaturgo concluye su prefacio con estas palabras que lo dicen todo:

Quiero decir, por último, que no hubiese podido escribir EL LÍMITE si otro antes que yo no hubiese descrito, con caracteres definitivos, una de las tantas luchas entre el bien y el mal que en nuestra patria fue la lucha entre la civilización y la barbarie. Su mano maestra ha guiado mi mano torpe; su genio, mi intención; su permanencia, mi transitoriedad. Ofrezco, pues, EL LIMITE a la gloria de Sarmiento (14). 
En ese prefacio, Zavalía deja bien en claro los fundamentos "ideológicos" de que ha partido para escribir su "tragedia en dos actos". Según su propio testimonio, la trama está basada en una leyenda que le oyó contar a su abuela tucumana, "cuyos padres -dice- fueron testigos de lo acaecido en aquella oportunidad" (10). Pero su idea de la tragedia, por más anclada que esté en la historia argentina (o en la leyenda), coincide con las de "universalidad", "ubicuidad" y "transhistoricidad" reseñadas en la primera parte de este trabajo: "Recurrir a la fuente legendaria me ha permitido, además, tratar de hacer de los personajes de EL LÍMITE arquetipos y símbolos, y que su tragedia, aun cuando ocurre en un tiempo y lugar determinados, sea una tragedia de cualquier tiempo y de cualquier lugar" (10).

Y que la última "fuente" de su tragedia es la Antígona sofoclea queda también indicado por el mismo Zavalía. En efecto, en El límite chocan "la pasión de la libertad en la heroína y la pasión del poder tiránico en el antihéroe” (11):

EL LÍMITE es una tragedia, y como en toda obra de ese género su planteo es "sub specie aeternitatis". A Fortunata y a Oribe los manejan las mismas fuerzas que manejaron a Antígona y a Creón. EL LÍMITE, en última instancia, no es otra cosa que un episodio entre la libertad y la tiranía, lucha tan antigua y duradera como la humanidad, que se libra constantemente y en todas partes: en nuestra América, en la vieja Europa, en Oriente. Lo mismo ayer, que hoy y mañana (11).

En el general Oribe, en Avellaneda y en Fortunata García se dan cita lo universal, lo de todo tiempo y lugar, y lo nacional, lo que de específicamente argentino tiene lo sucedido en aquellos dos días de octubre de 1841 en la ciudad de Tucumán. Oribe no es solamente un militar al servicio de Rosas, uno de los tantos caudillos que "asolaron nuestra tierra en los tiempos de barbarie en que ocurre EL LÍMITE”, sino también un “compendio, síntesis, arquetipo de los tiranos de todo tiempo y lugar, y de los tiranos y tiranuelos que padeció nuestra patria" (13). Fortunata es un "compendio y arquetipo de las sucesoras de Antígona” y la semejanza entre ambas "consiste, en lo exterior, en que las dos se proponen enterrar unos despojos mortales, y en lo interior, en que a ambas las mueve un dogma" (13): "A la doncella tebana, uno de carácter religioso: los muertos insepultos no alcanzan la otra vida; a la dama tucumana, uno de carácter ético y moral: fuera de la libertad no hay vida. Y las dos poseen una fuerza irresistible..." (13).

Como Marechal en Antígona Velez y Cureses en La cabeza en la jaula, Zavalía reescribió el drama de Sófocles desde la antinomia civilización / barbarie, pero hay otras obras y otro mito que habría que estudiar junto a estos tres dramas. En efecto, La frontera (1960) del mismo Cureses, cuya acción tiene lugar durante la Campaña del Desierto de la década de 1870, y La hechicera (1996) de José Luis 
Alves (1963-), drama que se desarrolla en Tucumán durante la época colonial, reescriben otro mito, el de Medea, y se basan también, sobre todo la primera, en la misma oposición que desde Sarmiento viene acuciando al pensamiento argentino.

Para concluir, cabe indicar que sería muy interesante estudiar otro drama que tiene también lugar durante la época de Rosas y cuya acción transcurre en 1840, pero sin referencias ni fundamentos míticos, ni fuentes clásicas, ni antecedentes en el teatro griego. Se trata de La malasangre de Griselda Gambaro, obra estrenada en Buenos Aires en 1982 y en la que se presenta la misma visión de la Argentina bajo el gobierno rosista, la que, para citar un solo caso más, José Mármol (1817-1871) ya había desarrollado extensamente en su novela Amalia (1855).

Excede los límites de esta contribución responder a los siguientes interrogantes, que merecen un tratamiento aparte: ¿por qué estos dramaturgos reescriben la historia desde los mitos griegos?, ¿`se alcanza, o no, una comprensión "más profunda" del pasado rosista en El límite que en La malasangre?, ¿la "transhistoricidad" del mito de Antígona permite entender aquellos hechos de octubre de 1841 en Tucumán "mejor" que los de Buenos Aires del año anterior? Y en cuanto a Gambaro, hay que recordar que también recreó la tragedia sofoclea en su Antigona furiosa (1986), desde contextos de producción y recepción muy distintos a los de Marechal, Zavalía y Cureses. 


\section{Bibliografía}

Butler, C. (2002), Post-modernism: A Very Short Introduction. Oxford: University Press.

Lyotard, J. F. (1979), La condition postmoderne: rapport sur le savoir. Paris: Les Editions de Minuit.

Martindale, C. (2007), "Reception", in Kallendorf, C. W. (ed.), A Companion to the Classical Tradition. Malden, MA, Blackwell: 297-311.

Mee, E. B. and Foley, H. P (2011), "Mobilizing Antigone”, Mee, E. B., Foley, H. P. (eds.), Antigone on the Contemporary Stage. Oxford, University Press: 1-47.

Pianacci, R. E. (2008), Antigona: una tragedia latinoamericana. Irvine, California: Gestos.

Segal, C. (1986), Interpreting Greek Tragedy: Myth, Poetry, Text. Ithaca and London: Cornell University Press.

Steiner, G. (1996), Antigones. New Haven and London: Yale University Press.

Vernant, J.-P. (1974), Mythe et société en Grèce ancienne. Paris: François Maspero.

Zavalía, A. de (1971), El límite: Tragedia en dos actos. Buenos Aires: Librería Huemul. 